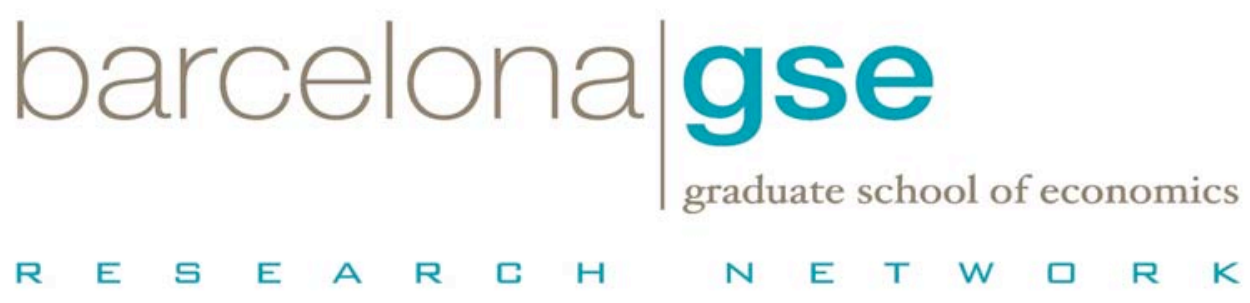

\title{
The Incentive Effects of Affirmative Action in a Real-Effort Tournament
}

\author{
Caterina Calsamiglia \\ Jörg Franke \\ Pedro Rey-Biel
}

July 20, 2009

Barcelona Economics Working Paper Series

Working Paper $n^{\circ} 404$ 


\title{
The Incentive Effects of Affirmative Action in a Real-Effort Tournament ${ }^{*}$
}

\author{
Caterina Calsamiglia ${ }^{+}$ \\ U. Autònoma de Barcelona
}

\author{
Jörg Franke ${ }^{1}$ \\ TU Dortmund
}

\author{
Pedro Rey-Biel $^{* *}$ \\ U. Autònoma de Barcelona
}

First draft: June 17, 2009

This version: July 20, 2009

\begin{abstract}
Affirmative-action policies bias tournament rules in order to provide equal opportunities to a group of competitors who have a disadvantage they cannot be held responsible for. Critics argue that they distort incentives, resulting in lower individual performance, and that the selected pool of tournament winners may be inefficient. In this paper, we study the empirical validity of such claims in a real-effort pair-wise tournament between children from two similar schools who systematically differ in how much training they received ex-ante in the task at hand. Our results show that performance was not reduced for either advantaged or disadvantaged subjects and that it was in fact enhanced. Additionally, while affirmative action balanced the proportion of disadvantaged individuals winning their respective tournament, the average performance of the pool of winners only decreased slightly.
\end{abstract}

Keywords: Affirmative action, tournament, real-effort, experiment, sudoku.

JEL classification: C72; C91; J78; M52

\footnotetext{
* We are especially grateful to Antoni Calvó-Armengol for his support and encouragement on this project. We thank Jose Apesteguia, Miguel A. Ballester, Carmen Beviá, Jeanette Brosig, Antonio Cabrales, Marta García-Matos, Maureen Gleeson, Uri Gneezy, Guillaume Haeringer, Nagore Iriberri, Inés Macho-Stadler, Muriel Niederle, Carmit Segal, Tom Palfrey, Neslihan Uler and seminar audiences at Rady School of Management, UC San Diego, Yale University, Universidad Pablo de Olavide, Università di Padova, Universidad de Navarra, Universität Trier, Universitat Autònoma de Barcelona, IMEBE (Alicante), ESA Tucson 2008, IESA Washington 2009 and the Conference in Memoriam of Antoni Calvó-Armengol for their comments. We are deeply grateful to the directors, faculty and administrative personnel at Agora, Aula, Colegio Alemán, Emili Juncadella, Pegaso and Sagrado Corazón for their understanding, permission and help with the experiments. We thank Pau Balart, Julen Berasaluce, Ignacio Fernández, Markus Kinateder, Tomasso Majer, Luca Merlino and Natalia Montinari for their help in running the experiments. Caterina Calsamiglia acknowledges financial support by a Ramón y Cajal contract of the Spanish Ministerio de Ciencia y Tecnología, through the Spanish Plan Nacional I+D+I (SEJ2005-01481, SEJ2005-01690 and FEDER), and through the "Grupo Consolidado de tipo C" (ECO2008-04756), the Generalitat de Catalunya (SGR2005-00626 and the Barcelona Economics Program of XREA), and the Consolider-Ingenio 2010 (CSD200600016) program. Jörg Franke acknowledges financial support from Ministerio de Educación y Ciencia (SEJ200501481/ECON) and FEDER, from Generalitat de Catalunya (2005SGR00454) and from Universitat Autònoma de Barcelona. Pedro Rey-Biel acknowledges financial support from Ministerio de Educacion y Ciencia (SEJ2006-00538 and Consolider-Ingenio CSD2006-00016), Barcelona GSE Research Network and of the Government of Catalonia (2005SGR-00836).

${ }^{+}$Caterina Calsamiglia. Universitat Autònoma de Barcelona. Department d'Economia i d’Historia Econòmica. 08193, Bellaterra. Barcelona (Spain). E-mail: caterina.calsamiglia@uab.cat.

${ }^{1}$ Jörg Franke, Department of Economics and Social Science, TU Dortmund, 44227 Dortmund, Germany. Tel.: (+49) 231755 3246. E-mail: joerg.franke@tu-dortmund.de.

** Pedro Rey-Biel. Universitat Autònoma de Barcelona. Department d'Economia i d'Historia Econòmica. 08193, Bellaterra. Barcelona (Spain). Tel: (+34) 935812113. E-mail: pedro.rey@uab.cat.
} 


\section{Introduction}

In many selection processes such as university admissions, job promotions and procurement auctions the competition generated serves the important purpose of identifying the highest-ability individuals and facilitating the correct allocation of talent in society. This objective may not be achieved if some talented individuals are discriminated against and do not have the same capacities to compete. For example, talented students from poor economic backgrounds may have attended high schools that receive less funding, which may affect their SAT performance and hence their university admission. Likewise, some individuals may belong to historically discriminated groups, and have to overcome major obstacles in order to be on an equal footing to compete.

Affirmative Action policies (AA) have two main objectives: to guarantee that positions are fairly allocated in society and to allow for the correct identification of talent. AA policies take proactive steps to provide equal opportunities to discriminated groups that have a potential disadvantage. ${ }^{2}$ They are often implemented by biasing tournament rules in order to increase the probability of success of a disadvantaged group. For example, a fixed lump-sum bonus of 20 (out of 150) points was added to the score of minority applicants to the undergraduate program at the University of Michigan and a similar but "unofficial lift" scheme is used at many top universities. ${ }^{3}$ In public procurement auctions bid preferences are granted in a multiplicative way. For example, road construction contracts in California are auctioned off by granting a 5\% reduction of the submitted bid to small business enterprises.

The implementation of AA is usually accompanied by intense public debate focusing on whether such policies satisfy certain fairness criteria and on the possible incentive distortions they may create. Abstracting from fairness considerations, opponents of AA base their criticism on two grounds. First, advantaged individuals may be discouraged by the preferential treatment of their (disadvantaged) rivals, leading to lower performance. Consequently, disadvantaged individuals may anticipate this reaction by their opponents or perceive AA as a substitute for their own effort, also

\footnotetext{
${ }^{2}$ Merriam-Webster Online defines affirmative action as "an active effort to promote the rights or progress of minority groups or other disadvantaged persons".

${ }^{3}$ This procedure was recently ruled to be unconstitutional by the Supreme Court, due in part to alleged distortionary effects on incentives that such compensation may create. State funded universities such as California, Florida and Texas have also applied similar measures in the past.
} 
leading to lower performance. ${ }^{4}$ Second, opponents argue that the pool of selected individuals, that is, the pool of winners, may be of poorer quality since lowerperforming individuals may now be selected. On the other hand, advocates of AA argue that leveling the playing field in a competitive environment may have positive effects on performance because AA reduces the asymmetry in capacities to compete, which increases competitive pressure and therefore enhances performance.

Surprisingly, both positions fail to base their views on solid empirical findings since very little research in economics provides empirical evidence on whether AA improves or worsens performance or on how it affects the pool of selected individuals. ${ }^{5}$ In this paper, we present results from a pair-wise real-effort tournament in which there exists a naturally induced source of disadvantage for one group of competitors, and where two different types of AA policies are implemented to compensate for it. ${ }^{6}$

We designed pair-wise tournaments among children from two similar schools which differ in how experienced their students are in the real-effort task on which the competition is based, i.e., solving simple numerical puzzles known as "sudokus."7 Students in one school ("experienced") are taught how to solve sudokus as part of their regular math classes, while students in the other school ("non-experienced”) are not. ${ }^{8}$ The schools are very similar in other relevant respects: both are private, fully bilingual and have good records in national math and science competitions. Therefore, the difference in experience can be regarded as an exogenous source of disadvantage since it is most likely not the reason why parents chose one particular school over the other. First, we study whether knowing that such an asymmetry in experience exists affects the performance of both experienced and non-experienced individuals. To study this question we adopt a baseline treatment where no AA is implemented and where subjects were unaware of the existence of an asymmetry in experience. We compare the

\footnotetext{
${ }^{4}$ See, for example, the introductory remarks in Sowell (2004) and the discussion in Fryer and Loury (2005b) of "Myth No. 3: Affirmative action undercuts investment incentives".

${ }^{5}$ One exception is Schotter and Weigelt (1992), which we discuss below. Also, see Holzer and Neumark (2000) for a survey.

${ }^{6}$ We chose pair-wise tournaments versus multiple-prize tournaments with $\mathrm{N}$ players for several reasons. First, and most importantly, the schools involved did not want us to establish intra-school competitions. Second, we wanted all subjects to be equally uninformed about the possible performance of their rivals. Finally, it allows us to relate our results to the existing theoretical models on pair-wise tournaments using AA.

${ }^{7}$ Sudoku is a logic-based number-placement puzzle. The objective is to fill a 9x9 grid so that each column, each row and each of the nine $3 \times 3$ boxes contains one-digit numbers from 1 to 9 only once. The puzzle setter provides a partially completed grid. We use a simplified $4 \times 4$ grid version in order to obtain sufficient variability in performance.

${ }^{8}$ Coate and Loury (1993) show how discrimination may arise in two symmetric groups as a self-fulfilling prophecy. In our case the asymmetry is exogenously given.
} 
respective results with an alternative treatment where the difference in experience is made salient. Second, in treatments where subjects are aware of the asymmetry in experience, we implement two types of compensation-lump-sum and proportional bonuses - designed to equalize on average the probability of non-experienced students beating their experienced rivals. ${ }^{9}$ We then study how performance by students from both schools is affected by the implementation of AA and whether the output of the new pool of tournament winners differs from the one obtained without any form of compensation.

The closest theoretical papers that explicitly address the incentive effects of affirmative action are Fu (2006), Franke (2008), Balart (2009) and Hickman (2009). They model affirmative action as a bias in favor of ex-ante disadvantaged players in an all-pay auction or contest set-up. Except for Hickman (2009), and in line with the simple model we present in Section 3, the conclusion that can be drawn from these papers is that reducing asymmetry in competitive advantage tends to enhance individual performance. ${ }^{10}$ Also, Fryer and Loury (2005a) show that optimal affirmative action in winner-take-all tournaments should involve handicapping. This result is not restricted to the affirmative action framework since similar results were first established for rankorder tournaments in Lazear and Rosen (1981), or for optimal auctions in Myerson (1981), where it is shown that favoring weak players might induce efficient allocations or maximization of expected revenue, respectively. ${ }^{11}$

There is a large empirical literature on tournaments and specifically on how the size of prizes affects competition (see Prendergast (1999) for a survey). With respect to affirmative action in tournaments, Niederle et al. (2008) study the effects of quotas on tournament participation of women. Miller and Segal (2008) analyze the long-term effects of affirmative action on the pool of hired law enforcement officers in the US. Finally, in the context of road construction contracts, Krasnokutskaya and Seim (2007) and Marion (2007) show that bid preferences for small businesses, in addition to balancing the asymmetry of entrants, induce higher procurement costs because the entry decisions of large low-cost firms are distorted.

\footnotetext{
${ }^{9}$ Calsamiglia (2009) shows that an appropriately designed AA policy should equalize rewards to effort whenever the set-up affects one of many factors determining individual final welfare.

${ }^{10}$ Hickman (2009) introduces an adapted equilibrium concept to conclude that lump-sum AA measures worsen performance in the context of an asymmetric all-pay auction with infinite players and prizes.

${ }^{11}$ Che and Gale (1998) study how in an all-pay auction with asymmetric players the inclusion of a cap on the size of bids may increase both players' bids.
} 
Schotter and Weigelt (1992) study the incentive effects of AA in experimental tournaments in a laboratory set-up where effort exertion is modeled as an individual decision problem based on monetary costs. Subjects' exogenous disadvantage is induced by assigning different cost parameters for which individuals are later compensated by affirmative action. This procedure makes it possible to vary the size of the asymmetry and tailor the compensations in order to exactly level the playing field. In line with the theoretical predictions in Section 3, the results obtained indicate that AA can either boost or worsen performance depending on the sizes of the cost disadvantage and the compensation implemented. In our study, the incentive effects of AA policies are analyzed in a real-effort tournament where the asymmetry between subjects existed ex-ante and was not induced by the experimentalist. Since we did not have an exact exante measure of the size of the asymmetry, we relied on results from pilot experiments to roughly calculate two different types (and sizes) of compensations, which on average level the playing field. ${ }^{12}$

The subjects in our experiment were school children. They were unaware that their choices were the object of a study since the experiment was presented as an extracurricular activity of a type not uncommon in the schools we selected. Using children as subjects has additional advantages: they react very spontaneously in competitive situations; their performance is not affected by them questioning the underlying motivation of the experimentalist; and it is relatively easy to provide them with incentives. It has also been shown that children react rationally and in line with economic theory (see Harbaugh et al. (2001) and Harbaugh and Krause (2000)). Finally, studying how children react to affirmative action is important since many social asymmetries may be ideally resolved at these early ages, before they are exacerbated. ${ }^{13}$

The experimental results of our study suggest that the implementation of AA policies does not necessarily have an adverse effect on the performance of affected individuals. First, we find that knowledge of the existence of an asymmetry in ability in fact increases performance. Most importantly, when such asymmetry is corrected through AA policies, performance by both advantaged (experienced) and disadvantaged (non-experienced) individuals increases even more. We show that increases in

\footnotetext{
${ }^{12}$ Several recent experimental studies employ similar strategies based on naturally occurring differences in characteristics among social groups. Examples are Hoff and Pandey (2006), where social caste differences are exploited, as well as Gneezy et al. (2003), and Niederle and Vesterlund (2007), where the performance of women versus men and their respective propensity to compete in mixed-gender tournaments is analyzed. Niederle et al. (2008) combine this insight on gender differences with participation decisions by individuals in an affirmative-action framework based on gender quotas.

${ }^{13}$ Gneezy and Rustichini (2004) show that boys and girls react differently to competition at a young age.
} 
performance differ depending on individual level of ability. In particular, nonexperienced individuals with relatively higher ability and experienced individuals with relatively lower ability exhibit the largest increases in performance, which may be explained by the fact that they are the ones most directly affected by the implementation of AA. We also find that AA affects boys and girls differently depending on their ability, and that it positively increases the confidence in winning of non-experienced subjects, while that of experienced subjects is unaffected. Finally, we show that the average performance of tournament winners selected through AA is only marginally lower than the average performance of the winners who would have been selected without it.

The rest of the paper is organized as follows. Experimental design and procedures are explained in Section 2. Section 3 describes a theoretical model that illustrates the effects that the type and extent of affirmative-action policies may have on performance. Section 4 presents the results. Section 5 sums up our conclusions. The Appendix contains the instructions used in the experiment.

\section{Experimental Design and Procedures}

We conducted pair-wise tournaments among 337 school children, aged 10-13, from two similar non-religious, bilingual private schools located in the same upper-class neighborhood of Barcelona. Students at both schools have a systematic difference in experience of a specific real-effort task consisting in solving simple "sudokus”. This exante difference in experience is due to the fact that during regular math classes, students in the "experienced” school (E) are trained in solving sudokus (and in fact have to solve sudokus as part of their regular homework) while students at the "non-experienced" school (NE) are not. ${ }^{14}$

Each student from E was randomly and anonymously matched with a student from NE in his or her same school year ( $4^{\text {th }}$ or $6^{\text {th }}$ grade). Each pair competed in a tournament that lasted 30 minutes. Subjects had to solve as many simple $4 \times 4$ sudokus as possible correctly in order to beat their matched rival. To do so, a whole grid had to be filled in with numbers from 1 to 4 in such a way that the same number could only appear once in each column, row or box in the grid. We chose this task because the

\footnotetext{
${ }^{14}$ An ex-post experimental questionnaire showed that some students from both schools were familiar with sudokus due to private experience. In fact, results from pilot experiments, in addition to the present one, show that subjects from NE were in fact disadvantaged in the competition (see section 4.1). The task was defined as "filling in a grid" and the word "sudoku" was never mentioned.
} 
rules are simple, yet it requires substantive logical reasoning and concentration by the subjects. Additionally, performance is easy to measure and, crucially, depends on effort. Most importantly, both effort and ability play a role, so that non-experienced subjects still have a chance of winning, independently of whether they are favored by an affirmative action policy or not. ${ }^{15}$

All subjects were handed the same answer sheet containing 96 sudokus randomly generated with the same level of difficulty by a computer program. ${ }^{16}$ Figure 1 below shows one of the sudokus used in the experiment (a) and its solution (b).

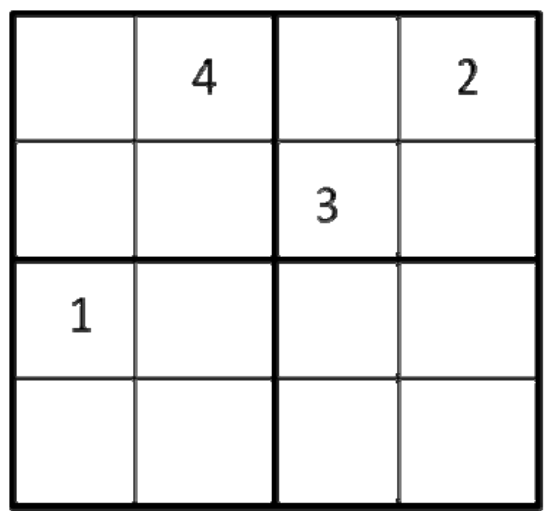

(a) Unsolved Sudoku

\begin{tabular}{|l|l|l|l|}
\hline 3 & 4 & 1 & 2 \\
\hline 2 & 1 & 3 & 4 \\
\hline 1 & 2 & 4 & 3 \\
\hline 4 & 3 & 2 & 1 \\
\hline
\end{tabular}

(b) Correctly Solved Sudoku

Figure 1: An example of the real-effort task (sudoku).

Each pair of subjects was competing for a $7 €$ (euro) voucher from a bookshop located in Barcelona. ${ }^{17}$ In each pair, the student who had correctly solved more sudokus during a 30 minute period won the voucher. In the case of ties, the winner was decided randomly.

Our objective was to study: 1) the effect of providing information on competitors' previous experience with the task and 2) the effect of implementing affirmative action policies on subjects' performance and as a result, on the output generated by subjects selected as tournament winners. Thus we randomly assigned similar numbers of subjects from each school to each of six treatments. In treatment NK no subject was informed about whether subjects from the other school were experienced or not in solving sudokus. In treatment $\mathrm{K}$ students at the NE school were told that

\footnotetext{
${ }^{15}$ In fact, the percentage of $\mathrm{NE}$ winners in their respective tournament was at least $13.3 \%$ (for experimental treatment " $K$ " and $4^{\text {th }}$ year students, where no affirmative action was implemented).

${ }^{16}$ The software used was "SuDoku Pro" by Dualogy Systems. The proportion of mistakes across all solved sudokus was similar. No subject was able to complete all 96 sudokus provided.

${ }^{17}$ Subjects were explicitly told that the voucher was redeemable for "books, collector's cards, toys, music or comics". Experiments took place at approximately the time the final Harry Potter book was published in Spain.
} 
students in the E school had previous experience in solving sudokus. Similarly, students in the E school were told that students at the NE school were not taught how to solve sudokus. In the remaining four treatments all subjects were informed about the difference in experience across schools and about the particular affirmative action policy applied to NE subjects. In treatments LH (Lump-sum High) and LL (Lump-sum Low), NE subjects were given a predetermined number of solved sudokus ex-ante: 20 in LH and 8 in LL. In treatments PH (Proportional High) and PL (Proportional Low), NE subjects were given a number of solved sudokus proportional to the number of sudokus they correctly solved, one for every correctly solved one in the case of $\mathrm{PH}$, and one for every two correctly solved ones in the case of PL. Comparisons across treatments NK and $\mathrm{K}$ allow us to study the effects of information when no affirmative action policies are implemented. Since, contrary to our expectations and as we shall show below, we did not find significant differences across all treatments where affirmative action is implemented (LL, LH, PL, PH), we shall pool the data from such treatments and refer to them generically as the “AA treatment”. Table 1 summarizes our treatment design. Comparisons across treatments $\mathrm{K}$ and $\mathrm{AA}$ allow us to study the effect on performance of applying affirmative action policies once the asymmetry in experience is known.

The sizes of the affirmative action policies were determined using results from pilot experiments. Since we were unaware of the exact size of the asymmetry between groups, we opted to choose two different sizes of each AA policy so that we could potentially observe how different sizes affect performance. At the same time, the objective was to design compensations that would on average equalize the chances of winning once the subjects reacted to the applied affirmative action policies. As shown below, on average the implemented policies roughly induced a "level playing field" expost (49\% of subjects from the NE school actually won their respective tournaments).

\begin{tabular}{|l|l|l|}
\hline \multicolumn{2}{|l|}{ Table 1: Description of Treatments } \\
\hline Not Know & NK & Subjects unaware of others' experience \\
\hline Know & K & Subjects aware of others' experience \\
\hline Lump-sum High & LH & Subjects aware of experience and NE subjects receive a bonus of 20 correct sudokus bonus \\
\hline Lump-sum Low & LL & Subjects aware of experience and NE subjects receive a bonus of 8 correct sudokus bonus \\
\hline Proportional High & PH & Subjects aware of experience and NE subjects receive 1 correct sudoku bonus for every 1 correct \\
\hline Proportional Low & PL & Subjects aware of experience and NE subjects receive 1 correct sudoku bonus for every 2 correct \\
\hline
\end{tabular}

Prior to conducting the experiments, we repeatedly met with faculty from both schools in order to guarantee their collaboration and pedagogical interest in the project. During these meetings we obtained information on subjects' gender, birth date, teaching 
group and school grades. We later assigned subjects to treatments in such a way that the groups were balanced in accordance with these pre-specified characteristics. Table 2 below shows descriptive statistics of subjects assigned to each treatment at each school. ${ }^{18}$ Small variations across treatments were mainly due to absent students and latecomers.

Table 2: Description of the Subject Pool

\begin{tabular}{|l|l|l|l|l|l|l|l|l|l|l|l|l|l|}
\hline & \multicolumn{9}{|c|}{ Experienced } & \multicolumn{5}{c|}{ Non-experienced } \\
\hline & NK & K & LH & LL & PH & PL & NK & K & LH & LL & PH & PL \\
\hline \% Female & 41 & 43 & 48 & 47 & 50 & 50 & 46 & 46 & 48 & 39 & 48 & 47 \\
\hline \% 6 ${ }^{\text {th }}$ Year & 48 & 43 & 45 & 46 & 46 & 47 & 50 & 46 & 59 & 47 & 48 & 59 \\
\hline Average Math Grade & 3.00 & 3.13 & 3.29 & 3.20 & 2.86 & 3.09 & 3.42 & 3.50 & 3.54 & 3.52 & 3.52 & 3.47 \\
\hline Number of subjects & 29 & 30 & 31 & 30 & 28 & 32 & 24 & 24 & 27 & 23 & 27 & 32 \\
\hline
\end{tabular}

Note: Average Math Grade is measured on a scale from 0 to 5.

Subjects were unaware of their participation in an experiment. With the help of each school faculty, it was explained to the subjects that this was an extracurricular activity, not dissimilar to previous ones carried out during the same school year. Participation was quasi-mandatory, which helped to avoid selection biases and simplified matters for the school. None of the subjects manifested opposition to participating.

Experiments were carried out on two separate but close dates at the two schools. In each school experimental sessions took place at different times of the day for 4th and 6th graders for practical reasons. ${ }^{19}$ Once subjects arrived at their school, they were conducted to separate classrooms according to our predefined assignment. While students waited for the experimentalist, teachers conducted a specific and identical school activity (writing an essay) in order to keep the subjects calm and equally uninformed about the experiment. The same experimentalist arrived at each of the classrooms at twenty-minute intervals and then sessions started. Teachers were not present during the experimental sessions, in order to minimize their influence. ${ }^{20}$

\footnotetext{
${ }^{18}$ Average Math Grade is slightly higher at the NE school than at the E school. The average math grade at the E school is 3.1 while at the NE school it is 3.49 , which is significantly different at the $1 \%$ level. Notice, however, that this is not necessarily an indicator of NE students being better at math, since the grading methodology may differ across schools and, in fact, grades in all other topics are also higher at the NE school.

${ }^{19}$ We are unaware of cross-contamination between schools or between subjects from different school years at the same school. The timing of the experiments was carefully designed so as to avoid these problems.

${ }^{20}$ This was the reason different treatments were carried out at different time-intervals. Since the experiment deals with effort motivation and children may be easily influenced, it was crucial to have the same experimentalist conducting the sessions. The experimentalist rehearsed repeating exactly the same cues across sessions.
} 
The experimental sessions lasted one hour. First, the experimentalist read out general instructions on how to solve sudokus (see "Pre-instructions" in the Appendix). Then, subjects had a five-minute practice round to solve sudokus. After this period, the experimentalist solved one of the practice sudokus in front of the students. Once questions were clarified, instructions for each of the treatments were read out. The instructions made it clear that each student was competing against an anonymous student from another comparable school and that students at the other school were systematically experienced (or not) in solving sudokus (for treatment NK this information was omitted). This difference in ex-ante experience was explicitly mentioned and was used to justify the implementation of the affirmative action bias in favour of the non-experienced group in treatments LL, LH, PL, and PH (see the Appendix for the instructions for one of these treatments). Tournament rules were explained giving numerical examples (specific to each treatment) for all potential outcomes of the tournament, i.e., losing, winning, and tying. Moreover, aggregate information with respect to the number of sudokus (i.e., mean, minimum and maximum) that had been correctly solved by a comparable subject pool was provided. This information, identical for all subjects, was based on the results of our pilot experiments. The experimentalist also held up a $7 €$ voucher to increase the credibility of the prize offered to tournament winners. After that, subjects had thirty minutes in which to solve the sudokus in two separate handouts. After the first fifteen minutes, subjects were instructed to start working on the second handout, so that we could measure whether there were intra-session learning effects or whether these were over-ruled by fatigue. ${ }^{21}$ Subjects were explicitly told that they could stop solving sudokus and start any other activity, such as drawing, so long as they kept quiet and did not bother others.

After the thirty minutes had passed, the handouts were collected and a questionnaire about previous experience in solving sudokus, self-confidence measures and the perceived justice behind affirmative action policies was distributed. Once the questionnaires had been filled in, subjects continued with their regular classes. The experimentalists then randomly matched participants from both schools, determined the winners and deposited the vouchers at the schools, to be distributed by school faculty.

\footnotetext{
${ }^{21}$ We did not find important differences in performance between the two parts of the test, indicating that the effects of learning and fatigue possibly cancel out. Experienced subjects completed one more sudoku in the second part (significant at the $1 \%$ level). Non-experienced subjects did not solve a significantly different number of sudokus in the two parts.
} 


\section{Theoretical Model}

We here abstract from psychological aspects and present a stylized noncooperative tournament model to illustrate how in the context of pair-wise tournaments the existence of an asymmetry in capacity to compete leads to poor performance and how both advantaged and disadvantaged individuals may be affected by different AA policies. ${ }^{22}$ Results crucially depend on the relative size of the asymmetry and the compensation implemented. $^{23}$

The model is based on a simple two-player rank-order tournament as presented in Schotter and Weigelt (1992), which is a simplified version of Lazear and Rosen (1981). The set-up is as follows: two heterogeneous players $i=1,2$ compete for a given prize with common value $V$ by exerting non-negative effort $e_{1}, e_{2}$. Heterogeneity affects the cost function and is due to some sort of disadvantage for the second player. In particular we assume that $c_{1}\left(e_{1}\right)=1 / 2 \cdot e_{1}^{2}$, while $c_{2}\left(e_{2}\right)=1 / 2 \cdot b \cdot e_{2}^{2}$ where $b>1 .^{24}$

Exerted effort by an agent is unobservable but generates observable output $y_{i}=e_{i}+\varepsilon_{i}$ for $i=1,2$ where $\varepsilon_{i}$ is a random variable which is assumed to be uniformly distributed between $-a$ and $a$. The decisive variable for the outcome of the tournament is output, i.e. only the agent with the highest output level will win the tournament and obtain the prize. Hence, the expected payoff for agents 1 and 2 in a tournament with affirmative action can be stated in the following way:

$$
\begin{aligned}
& \pi_{1}=\operatorname{Pr}\left[y_{1}\left(e_{1}\right)>y_{2}\left(e_{2}\right)+A A\right] V-\frac{e_{1}^{2}}{2} \text { and } \\
& \pi_{2}=\operatorname{Pr}\left[y_{2}\left(e_{2}\right)+A A>y 1\left(e_{1}\right)\right] V-b \frac{e_{2}^{2}}{2},
\end{aligned}
$$

where the affirmative action policy is captured by $A A$ and can take one of the following two forms:

1. Lump-sum AA, with $A A=L$, where $L$ is a positive constant.

\footnotetext{
${ }^{22}$ See, for example, Apesteguia and Palacios-Huerta (2008) for evidence on how psychological aspects may affect tournament performance in a natural setting.

${ }^{23}$ The model differs from the experimental design in that, in our experiment, neither the tournament designers nor the competitors were aware of the size of the asymmetry since some had never been exposed to the task before and therefore did not know the extent of the advantage for experienced subjects.

${ }^{24}$ Alternatively, the asymmetry can affect the productivity of effort (how effort converts into output) without altering qualitative results.
} 
2. Proportional AA, with $A A=P^{*} e_{2}$, where $P$ is a positive constant. ${ }^{25}$

The probability of winning for agent 1 can be reformulated as $\operatorname{Pr}\left(\varepsilon_{2}-\varepsilon_{1}<e_{1}-e_{2}-A A\right)$. Note that the composed random variable $\varepsilon=\left(\varepsilon_{2}-\varepsilon_{1}\right)$ has a triangular distribution with the following distribution function:

$$
F_{1}(x)=\left\{\begin{array}{l}
\frac{1}{2}+\frac{x}{2 a}+\frac{x^{2}}{8 a^{2}}, \text { for } \mathrm{x} \in[-2 a, 0] \\
\frac{1}{2}+\frac{x}{2 a}-\frac{x^{2}}{8 a^{2}}, \text { for } \mathrm{x} \in[0,2 a]
\end{array} .\right.
$$

The respective distribution function for agent 2 is: $F_{2}(x)=1-F_{1}(x)$.

In the interior equilibrium, the effort levels $\left(e_{1} *, e_{2} *\right)$ will satisfy the following first order conditions for both individuals:

$$
\begin{gathered}
\frac{\partial \pi_{1}}{\partial e_{1}}=\frac{\partial F_{1}\left(e_{1}^{*}-e_{2}^{*}-A A\right)}{\partial e_{1}} V-e_{1}^{*}=0, \\
\frac{\partial \pi_{2}}{\partial e_{2}}=\frac{\partial F_{2}\left(e_{1}^{*}-e_{2}^{*}-A A\right)}{\partial e_{2}} V-b^{*} e_{2}^{*}=0 .
\end{gathered}
$$

The equilibrium effort levels will thus depend on the format of the Affirmative Action policy. We now describe the equilibrium for each of the two designs.

\section{Lump-sum AA}

When affirmative action is lump-sum we obtain:

$$
\frac{\partial F_{1}\left(e_{1}^{*}-e_{2}^{*}-L\right)}{\partial e_{1}}=\left\{\begin{array}{l}
\frac{1}{2 a}+\frac{e_{1}^{*}-e_{2}^{*}-L}{4 a^{2}}, \text { for } e_{1}^{*}-e_{2}^{*}-L<0 \\
\frac{1}{2 a}-\frac{e_{1}^{*}-e_{2}^{*}-L}{4 a^{2}}, \text { for } e_{1}^{*}-e_{2}^{*}-L \geq 0
\end{array},\right.
$$

and vice versa for the second agent. Using these expressions and solving for $e_{1} *$ and $e_{2} *$ in the first order conditions we find that:

$$
\begin{gathered}
e_{1}^{*}=b e_{2}^{*}, \quad e_{2}^{*}=\frac{(2 a-L) V}{4 a^{2} b-(b-1) V}, \text { for } L>\frac{(b-1) V}{2 a b} \\
e_{1}^{*}=b e_{2}^{*}, \quad e_{2}^{*}=\frac{(2 a+L) V}{4 a^{2} b-(b-1) V}, \text { for } L \leq \frac{(b-1) V}{2 a b}
\end{gathered}
$$

We now analyze the effect of AA on the effort levels exerted on equilibrium. Comparative statics are carried out by taking derivatives of equilibrium effort levels with respect to $A A$, that is, with respect to $L$. Equilibrium effort levels first increase in

\footnotetext{
${ }^{25}$ An alternative specification of proportional AA would be to scale up output $y_{2}$ by factor $(1+P)$, i.e., $f\left(e_{2}\right)=(1+P)\left(e_{2}+\varepsilon_{2}\right)$. In this case the random error would also be affected by AA, which complicates the analysis but leads to the same qualitative results.
} 
the size of the bonus, until a maximum is reached when $L=\frac{(b-1) V}{2 a b}$, and then decrease. $^{26}$ This implies that the implementation of AA provides incentives to both agents so long as the bonus is not too high, in which case the advantage is reversed and incentives are reduced. That is, if the bonus helps to reduce the asymmetry then it increases incentives, but if it is too large it can reverse the advantage and reduce incentives again. $^{27}$

\section{Proportional AA}

Under proportional affirmative action the marginal probability of winning can be expressed as:

$$
\frac{\partial F_{1}\left(e_{1}^{*}-(1+P) e_{2}^{*}\right)}{\partial e_{1}}=\left\{\begin{array}{l}
\frac{1}{2 a}+\frac{e_{1}^{*}-(1+P) e_{2}^{*}}{4 a^{2}}, \text { for } e_{1}^{*}-(1+P) e_{2}^{*}<0 \\
\frac{1}{2 a}-\frac{e_{1}^{*}-(1+P) e_{2}^{*}}{4 a^{2}}, \text { for } e_{1}^{*}-(1+P) e_{2}^{*} \geq 0
\end{array},\right.
$$

while for agent 2 the equation is now slightly different:

$$
\frac{\partial F_{2}\left(e_{1}^{*}-(1+P) e_{2}^{*}\right)}{\partial e_{2}}=\left\{\begin{array}{l}
\frac{1+P}{2 a}+\frac{(1+P)\left[e_{1}^{*}-(1+P) e_{2}^{*}\right]}{4 a^{2}}, \text { for } e_{1}^{*}-(1+P) e_{2}^{*}<0 \\
\frac{1+P}{2 a}-\frac{(1+P)\left[e_{1}^{*}-(1+P) e_{2}^{*}\right]}{4 a^{2}}, \text { for } e_{1}^{*}-(1+P) e_{2}^{*} \geq 0
\end{array} .\right.
$$

Using these expressions and solving the first order conditions we find $e_{1} *$ and $e_{2}^{*}$ :

$$
\begin{aligned}
& e_{1}^{*}=\frac{b}{1+P} e_{2}^{*}, \quad e_{2}^{*}=\frac{2 a(1+P) V}{4 a^{2} b+\left((1+P)^{2}-b\right) V}, \text { for } \mathrm{P}>\sqrt{b}-1 \\
& e_{1}^{*}=\frac{b}{1+P} e_{2}^{*}, \quad e_{2}^{*}=\frac{2 a(1+P) V}{4 a^{2} b+\left(b+(1+P)^{2}\right) V}, \text { for } \mathrm{P} \leq \sqrt{b}-1
\end{aligned}
$$

26 The derivative of $e_{2}{ }^{*}$ with respect to $L$ is $\frac{d e_{2}^{*}}{d L}=\frac{-V}{4 a^{2} b-(b-1) V} \leq 0$, for $L>\frac{(b-1) V}{2 a b}$ and $\frac{d e_{2}^{*}}{d L}=\frac{V}{4 a^{2} b-(b-1) V} \geq 0$, for $L \leq \frac{(b-1) V}{2 a b}$.

${ }^{27}$ Schotter and Weigelt (1992) report that lump-sum Affirmative Action theoretically reduces effort, but this is because they only considered the case in which the compensation is relatively large, i.e., $L>\frac{(b-1) V}{2 a b}$. 
Again, carrying out comparative statics of equilibrium effort levels on the size of the AA policy, $P$, we find that for low levels of proportional bonus, $\mathrm{P} \leq \sqrt{b}-1$, the equilibrium effort levels increase with the size of the bonus. But if the bonus is high, $\mathrm{P}>\sqrt{b}-1$, increasing it further will decrease $e_{1} *$ and have ambiguous effects on $e_{2} *{ }^{28}$ As before, there exists a threshold value of $\mathrm{P}=\sqrt{b}-1$ which maximizes total effort and corresponds to the $\mathrm{P}$ which makes the competition exactly level.

To summarize, we find that affirmative action should increase the subjects' performance, no matter whether the compensation is lump-sum or proportional to performance, as long as the bonus reduces the asymmetry, that is, if it is not too large to induce reversed discrimination. Our experiment should not be understood as an attempt to test the predictive power of this simple and stylized theoretical model empirically. Rather, the model serves as an illustration of the potential effects which different types and sizes of affirmative action policies might possibly have.

\section{Results}

\subsection{Descriptive Statistics}

We start by taking a descriptive look at the data. Table 3 records the average number of correct sudokus by treatment and school year ( $4^{\text {th }}$ or $6^{\text {th }}$ grade) in each of the schools ( $E$ and $N E$ ). Note that there is high heterogeneity in performance in all treatments and thus, standard deviations are large. Table 3 provides a first indication that subjects from the experienced school (E) solve, on average, more sudokus, a key hypothesis justifying our experimental design. It also shows that subjects in more advanced grades perform better. Note that the average performance of $4^{\text {th }}$ grade experienced subjects in all treatments is similar to that of $6^{\text {th }}$ grade non-experienced subjects.

${ }^{28}$ For $\mathrm{P}>\sqrt{b}-1, \quad \frac{\partial e_{1}^{*}}{\partial P}=-\frac{4 a b(1+P) V^{2}}{\left(4 a^{2} b-\left(b+(1+P)^{2}\right) V\right)^{2}}<0 \quad$ and $\frac{\partial e_{2}^{*}}{\partial P}=\frac{1}{b}(1+P) \frac{\partial e_{1}^{*}}{\partial P}+\frac{1}{b} e_{1}^{*}$, which has an ambiguous sign. For $\mathrm{P} \leq \sqrt{b}-1, \frac{\partial e_{1}^{*}}{\partial P}=-\frac{4 a b(1+P) V^{2}}{\left(4 a^{2} b+\left(b-(1+P)^{2}\right) V\right)^{2}}>0$, and $\frac{\partial e_{2}^{*}}{\partial P}=\frac{1}{b}(1+P) \frac{\partial e_{1}^{*}}{\partial P}+\frac{1}{b} e_{1}^{*}>0$. 


\begin{tabular}{|c|c|c|c|c|c|c|}
\hline \multicolumn{2}{|c|}{ Table 3: Average Number (and Standard Deviations) of Correct Sudokus by Treatment and School Year } \\
\hline \multirow{2}{*}{} & \multicolumn{2}{|c|}{$4^{\text {th }}$ Grade } & \multicolumn{2}{c|}{$6^{\text {th }}$ Grade } & \multicolumn{3}{c|}{ Overall } \\
\cline { 2 - 7 } & E & NE & E & NE & E & NE \\
\hline NK & $\mathbf{2 8}$ & $\mathbf{1 6 . 9 8}$ & $\mathbf{3 8 . 9 2}$ & $\mathbf{2 4 . 6 6}$ & $\mathbf{3 3 . 2 7}$ & $\mathbf{2 0 . 3 8}$ \\
& $(15.43)$ & $(8.01))$ & $(16.10)$ & $(15.43)$ & $(16.44)$ & $(12.80)$ \\
\hline K & $\mathbf{2 9 . 9 4}$ & $\mathbf{1 7 . 6 9}$ & $\mathbf{4 3}$ & $\mathbf{2 9 . 0 9}$ & $\mathbf{3 5 . 6 0}$ & $\mathbf{2 2 . 9 2}$ \\
& $(12.45)$ & $(10.70)$ & $(17.97)$ & $(13.43)$ & $(16.21)$ & $(13.13)$ \\
\hline AA & $\mathbf{2 9 . 1 8}$ & $\mathbf{1 9 . 2 6}$ & $\mathbf{4 5 . 4 7}$ & $\mathbf{2 8 . 0 8}$ & $\mathbf{3 6 . 5 9}$ & $\mathbf{2 4 . 0 3}$ \\
& $(13.74)$ & $(9.48)$ & $(12.06)$ & $(12.12)$ & $(15.29)$ & $(11.80)$ \\
\hline LH & 28.47 & 23.36 & 44.29 & 29.50 & 35.67 & 27 \\
& $(11.89)$ & $(9.19)$ & $(11.86)$ & $(14.43)$ & $(14.19)$ & $(12.73)$ \\
\hline LL & 27.47 & 19.41 & 51.38 & 26 & 37.83 & 22.56 \\
& $(12.21)$ & $(11.79)$ & $(11.19)$ & $(9.01)$ & $(16.71)$ & $(10.85)$ \\
\hline PH & 29.60 & 17.92 & 44.69 & 26.53 & 37.54 & 22.07 \\
& $(12.45)$ & $(9.05)$ & $(11.09)$ & $(11.15)$ & $(14.50)$ & $(10.84)$ \\
\hline PL & 31.23 & 17.07 & 40.27 & 29.16 & 35.47 & 24.25 \\
& $(18.22)$ & $(7.59)$ & $(12.38)$ & $(12.83)$ & $(16.17)$ & $(12.42)$ \\
\hline
\end{tabular}

Figure 2 below shows the cumulative distribution function (CDF) of the number of correct sudokus solved by students in the E and NE school for the two treatments where AA measures are not implemented (NK and K). Note that the distributions have a large spread and range from 0 sudokus solved to more than 70. Stochastic dominance of the CDFs for the E school clearly shows that the lower level of experience in solving sudokus is in fact a disadvantage for the NE subjects. Mann-Whitney tests comparing the inter-school number of correct sudokus in both of these treatments show significant differences at the $1 \%$ level (p-values of 0.002 for NK and of 0.003 for $\mathrm{K}$ ).
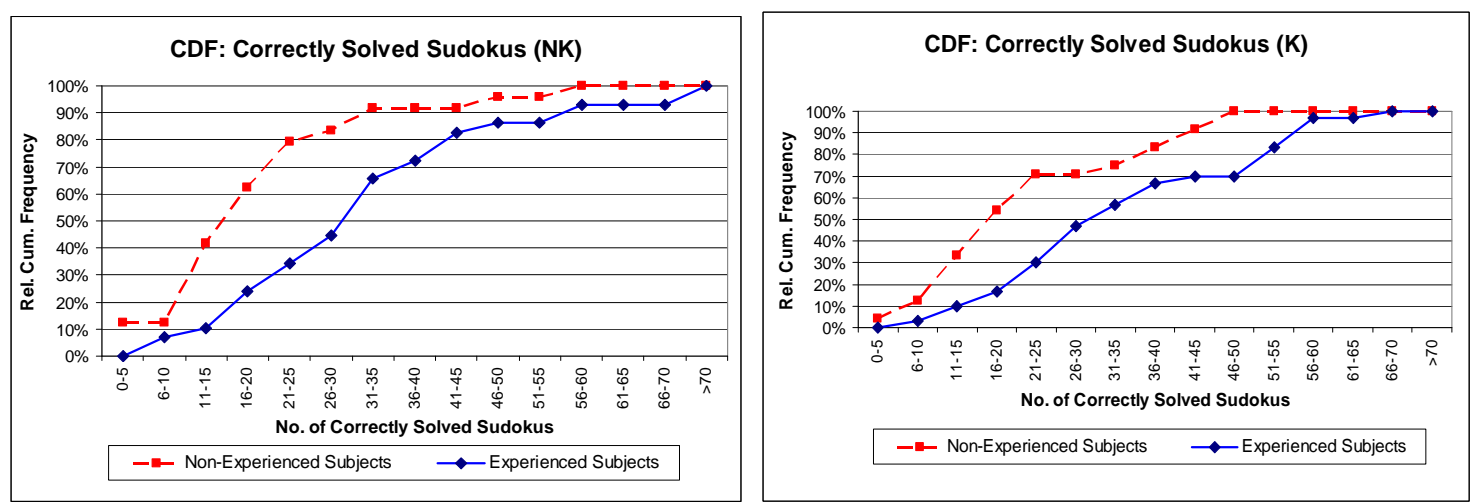

Figure 2: CDFs of the number of correct sudokus by $\mathrm{E}$ and NE in the NK and $\mathrm{K}$ treatments.

Intra-school comparisons across treatments are less clear-cut. Table 3 records the number of correctly solved sudokus both for the unpooled data for the treatments where affirmative action is implemented ( $\mathrm{LH}, \mathrm{LL}, \mathrm{PH}$ and $\mathrm{PL}$ ), and for the pooled data included under the AA label. Figure 3 depicts the CDFs for the number of correct sudokus for the NK, K and AA treatments in each of the two schools. Visually, the CDF for the K treatment "almost stochastically dominates” the CDF for the NK treatment in both graphs, suggesting that the provision of information on the existence of a disadvantaged group does not decrease performance, and in fact it may enhance it. Similarly, the CDFs for the AA treatment also lies below the CDFs for the NK 
treatment and generally not above the CDF for the $\mathrm{K}$ treatment in both schools, suggesting that subjects faced with AA policies do not decrease their performance, even in the case of the $\mathrm{K}$ treatment where they are aware of the disadvantage. Mann-Whitney tests comparing the distribution of all treatments do not generally show significant differences at the standard levels, apart from the comparison of NK with AA for $6^{\text {th }}$ year experienced subjects (average of 38.92 correct sudokus in NK and average of 45.47 in AA, p-value of 0.03).
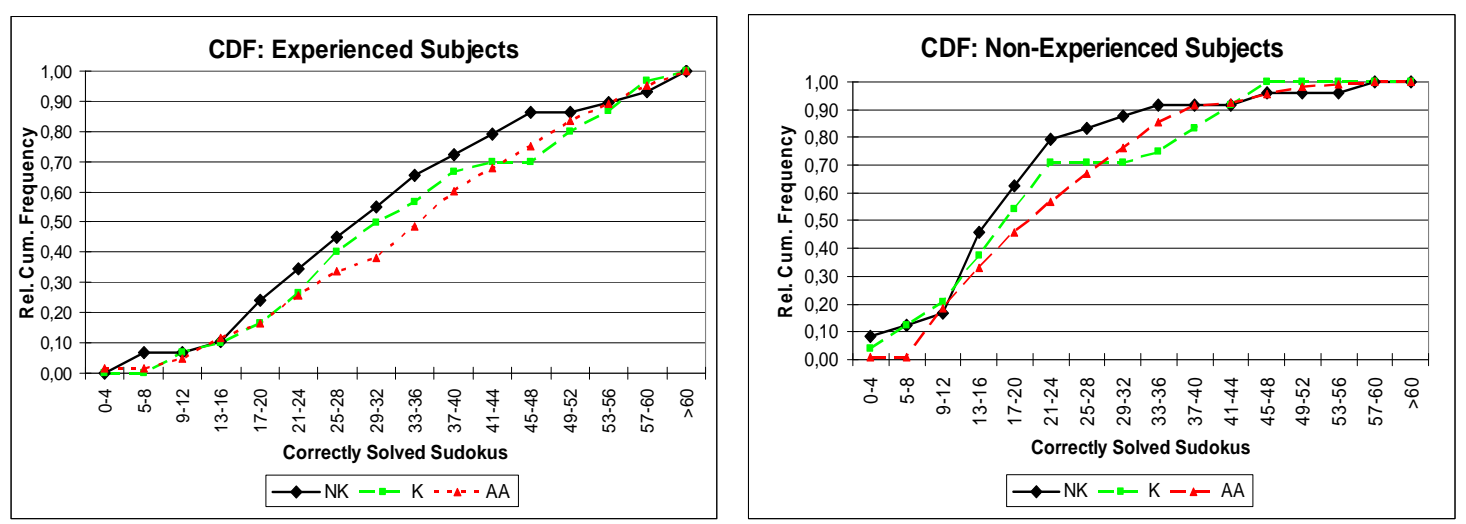

Figure 3: CDFs of the number of correct sudokus by school in the NK, K and AA treatments.

The joint Kruskal-Wallis test, as well as Mann-Whitney tests comparing the distribution of correctly solved sudokus in all four treatments where affirmative action is implemented (LH, LL, PH and PL), do not show statistically significant differences at the usual levels which, together with a graphical analysis using CDFs for all four treatments, supports the conclusion that different affirmative action policies (and sizes) did not have different effects on performance. Note that with respect to our theoretical model this may be interpreted as evidence that none of the compensations we used, no matter how high they seemed in our pilot experiments, were high enough to reverse the asymmetry between the two schools so as to reduce performance by subjects. Additionally, the theoretical model predicts similar effects for either lump-sum or proportional compensation. Therefore, in the following, we perform our analysis with both pooled and unpooled data for those treatments in which affirmative action is implemented.

Low levels of significance can be attributed to the high variance among the subjects in a given school. But part of this variance can be attributed to individual heterogeneity which we control for in the following section. 


\subsection{The Effects of Information and Affirmative Action on Performance}

In this section we study the effects of providing information on the ex-ante difference in experience between subjects and how performance in the tournament is affected by the implementation of AA policies, using suitable controls for individual heterogeneity. We run separate linear regressions for each school with the number of correctly solved sudokus as a dependent variable (Table 4). Our baseline treatment is K, where subjects are aware of the existing disadvantage but no AA policy is implemented. Explanatory variables are the AA treatment dummies (both unpooled and pooled in two separate regressions) and a dummy variable for treatment NK in order to control for the effect of not providing information on the asymmetry in experience. From the theoretical model presented above, differences in ability to compete should affect performance, independently of their potential source. Therefore, an important variable we need to control for is unobserved "ability". For a proxy we used the number of correct sudokus solved by subjects in a "Pretest", i.e., the five minute practice rounds that subjects performed before the competition was introduced. Additional regressors include several other individual characteristics such as "Gender", year of schooling ("Year"), and the math grade obtained by students in the previous term ("Grade”). ${ }^{29}$ Since we anticipated that AA may affect subjects differently depending on their level of ability, we included an interaction term (“AA*Pretest”). The inclusion of the interaction term implies that a representative subject of the base group under $\mathrm{K}$ has low ability (zero correct sudokus in the five minute trials). The regressions presented in table 4 show the results for both $\mathrm{E}$ and NE schools when controlling for the different AA treatments, pooled in the case of OLS (1) and (3) and unpooled in OLS (2) and (4).

\footnotetext{
29 Since "Pretest" and "Grade" may be interpreted as different but correlated measures of individual ability, we run separate regressions using just one variable as regressor. Qualitative results are maintained and statistical levels of significance are slightly improved.
} 


\begin{tabular}{|c|c|c|c|c|}
\hline & \multicolumn{2}{|c|}{ Experienced } & \multicolumn{2}{|c|}{ Non-Experienced } \\
\hline & $\begin{array}{c}\text { OLS (1) } \\
\text { Dep. Var: } \\
\text { \# Correct Sudokus } \\
\end{array}$ & $\begin{array}{c}\text { OLS (2) } \\
\text { Dep. Var: } \\
\text { \# Correct Sudokus } \\
\end{array}$ & $\begin{array}{c}\text { OLS (3) } \\
\text { Dep. Var: } \\
\text { \# Correct Sudokus } \\
\end{array}$ & $\begin{array}{c}\text { OLS (4) } \\
\text { Dep. Var: } \\
\text { \# Correct Sudokus } \\
\end{array}$ \\
\hline Constant & $\begin{array}{c}-12.96 \\
(4.43)^{* * *}\end{array}$ & $\begin{array}{c}-13.12 \\
(4.42)^{* * *}\end{array}$ & $\begin{array}{c}5.16 \\
(3.29) \\
\end{array}$ & $\begin{array}{c}5.22 \\
(3.34) \\
\end{array}$ \\
\hline NK & $\begin{array}{c}2.73 \\
(2.49)\end{array}$ & $\begin{array}{c}2.75 \\
(2.49)\end{array}$ & $\begin{array}{c}0.40 \\
(2.15)\end{array}$ & $\begin{array}{c}0.40 \\
(2.19)\end{array}$ \\
\hline AA & $\begin{array}{c}8.31 \\
(4.80)^{*} \\
\end{array}$ & - & $\begin{array}{l}-1.59 \\
(2.68) \\
\end{array}$ & - \\
\hline AA*Pretest & $\begin{array}{c}-1.64 \\
(0.96)^{*}\end{array}$ & - & $\begin{array}{c}1.45 \\
(0.56)^{* *}\end{array}$ & - \\
\hline $\mathrm{LH}$ & - & $\begin{array}{c}11.10 \\
(5.96)^{*}\end{array}$ & - & $\begin{array}{l}-3.83 \\
(4.10) \\
\end{array}$ \\
\hline LL & - & $\begin{array}{l}-1.66 \\
(8.19)\end{array}$ & - & $\begin{array}{l}-2.01 \\
(4.02)\end{array}$ \\
\hline $\mathrm{PH}$ & - & $\begin{array}{c}13.38 \\
(6.02)^{* *}\end{array}$ & - & $\begin{array}{c}-0.38 \\
(3.55) \\
\end{array}$ \\
\hline PL & - & $\begin{array}{c}1.39 \\
(7.20)\end{array}$ & - & $\begin{array}{l}-0.66 \\
(3.51)\end{array}$ \\
\hline LH*Pretest & - & $\begin{array}{c}-2.29 \\
(1.24)^{*}\end{array}$ & - & $\begin{array}{c}2.12 \\
(0.88)^{* *}\end{array}$ \\
\hline LL*Pretest & - & $\begin{array}{c}0.31 \\
(1.62) \\
\end{array}$ & - & $\begin{array}{c}1.58 \\
(1.03) \\
\end{array}$ \\
\hline $\mathrm{PH}^{*}$ Pretest & - & $\begin{array}{c}-2.17 \\
(1.23)^{*} \\
\end{array}$ & - & $\begin{array}{c}1.01 \\
(0.87) \\
\end{array}$ \\
\hline PL*Pretest & - & $\begin{array}{l}-0.58 \\
(1.45)\end{array}$ & - & $\begin{array}{l}1.12 \\
(0.81)\end{array}$ \\
\hline $\begin{array}{l}\text { Pretest } \\
(0=\text { Min, 6=Max in E) } \\
(0=\text { Min, 12=Max in NE) }\end{array}$ & $\begin{array}{c}6.96 \\
(0.81)^{* * *}\end{array}$ & $\begin{array}{c}6.95 \\
(0.81)^{* * *}\end{array}$ & $\begin{array}{c}3.34 \\
(0.42)^{* * *}\end{array}$ & $\begin{array}{c}3.34 \\
(0.43)^{* * *}\end{array}$ \\
\hline $\begin{array}{l}\text { Grade } \\
\text { (1=Worst,5=Best) }\end{array}$ & $\begin{array}{c}3.33 \\
(0.72)^{* * *} \\
\end{array}$ & $\begin{array}{c}3.43 \\
(0.72)^{* * *} \\
\end{array}$ & $\begin{array}{c}0.45 \\
(0.70) \\
\end{array}$ & $\begin{array}{c}0.45 \\
(0.71) \\
\end{array}$ \\
\hline $\begin{array}{l}\text { Year } \\
\left(0=4^{\text {th }}, 1=6^{\text {th }}\right)\end{array}$ & $\begin{array}{c}12.03 \\
(1.63)^{* * *}\end{array}$ & $\begin{array}{c}11.77 \\
(1.65)^{* * *}\end{array}$ & $\begin{array}{c}4.14 \\
(1.24)^{* * *}\end{array}$ & $\begin{array}{c}4.28 \\
(1.28)^{* * *}\end{array}$ \\
\hline $\begin{array}{l}\text { Gender } \\
(0=\text { Male, } 1=\text { Female })\end{array}$ & $\begin{array}{c}1.99 \\
(1.40) \\
\end{array}$ & $\begin{array}{c}2.05 \\
(1.41) \\
\end{array}$ & $\begin{array}{c}1.04 \\
(1.19) \\
\end{array}$ & $\begin{array}{c}0.76 \\
(1.25) \\
\end{array}$ \\
\hline \# Observations & 180 & 180 & $155^{\mathrm{a}}$ & $155^{\mathrm{a}}$ \\
\hline Adj. $\mathrm{R}^{2}$ & 0.65 & 0.66 & 0.65 & 0.64 \\
\hline
\end{tabular}

Notes: * denotes significance at the $10 \%$ level, ** denotes significance at the $5 \%$ and *** at the $1 \%$ level.

(a): For one non-experienced subject "Grade” was not available. Another subject arrived late and did not participate in the practice rounds. Such observations are omitted from OLS (3) and OLS (4).

Our proxy for unobserved ability as measured by results in the practice rounds ("Pretest"), being in sixth grade instead of fourth grade ("Year"), and math grades ("Grade") have all positive and significant effects, ${ }^{30}$ while the effect of "Gender" is not significant. Note that the coefficients for the NK dummy variable are not significant in any of the regressions which, together with Figure 3, allows us to conclude:

Result 1: Knowledge of the existence of an asymmetry in experience does not decrease performance by experienced or non-experienced subjects.

\footnotetext{
30 “Grade” is not statistically significant for NE subjects.
} 
We now focus on the effect of affirmative action on performance, starting with the experienced subjects (E). OLS (1) shows that when pooling all affirmative action treatments, the coefficient for AA has a positive and significant impact (at the $10 \%$ level), i.e., experienced subjects in the base group (with low ability) statistically solve 8.31 sudokus more if they compete with subjects favored by an affirmative action policy. However, the higher the ability of the experienced subject (measured by "Pretest"), the lower the increase in AA performance, since the interaction term (“AA*Pretest”) is negative and significant (at the $10 \%$ level). ${ }^{31}$ For subjects with the highest ability the performance-enhancing effects of AA are nullified or even slightly negative. $^{32}$ This result suggests that those experienced subjects who realize that they may now not win their respective tournament once non-experienced subjects are receiving help, are precisely the ones who react most strongly to competitive pressure. On the other hand, experienced subjects with high ability may have fewer reasons to react, since they may win their respective tournament anyway. The unpooled analysis of the AA treatments in OLS (2) generally shows the same signs (apart from the highly non-significant LL treatment) although significance is low, which may partially be due to the lower sample size. In any case, the more intensive AA treatments, i.e. LH and $\mathrm{PH}$, are the main contributors to the described incentive effects. We thus conclude:

Result 2: Affirmative Action policies enhance the performance of experienced subjects. The lower the individual ability of the experienced subject, the higher this effect.

We now focus on the non-experienced subjects (NE). Note that as before, the inclusion of the interaction term ("AA*Pretest”) implies that a subject in the base group has low ability. For the pooled data (OLS (3)) the coefficient of “AA” for low ability subjects is negative although not statistically significant from zero. Hence, low ability subjects do not react to AA, i.e. AA on its own does not reduce the performance of non-

31 The statistical effect of AA on subjects with higher ability can therefore be calculated as "AA"+"AA*Pretest".

${ }^{32}$ We did not anticipate that experienced subjects would solve more than 6 sudokus in their 5 minute practice rounds. Thus, experienced subjects were provided with only 6 sudokus as part of their trial. Forty percent of the subjects solved all 6 correctly. For this reason our measure of ability for experienced subjects is cut off at 6 , since it includes individuals who would possibly have solved more than 6 sudokus. We thus expect that our estimated parameters are smaller and less significant (due to higher variance) in comparison to properly specified trials with a larger number of sudokus. For the subsequently run experimental sessions with non-experienced subjects, we extended the number of trial sudokus to 12. By truncating these data artificially in the same manner as for experienced subjects, we were able to verify the conjecture that results become slightly less significant and weaker in absolute size without altering the qualitative results when there are fewer sudokus in practice rounds. 
experienced subjects with low ability. This result is substantively different for subjects with higher abilities as shown by the positive and significant coefficient at the $5 \%$ level of the interaction term (“AA*Pretest”): subjects with higher ability solve significantly more sudokus with AA than without it, i.e. each extra correct sudoku in the practice round implies 1.45 more correct sudokus in the tournament if AA is implemented. ${ }^{33} \mathrm{We}$ thus conclude:

Result 3: Affirmative Action policies do not decrease the performance of nonexperienced subjects. In fact, AA increases the performance of these subjects with the exception of those of lowest ability. The higher the ability of the non-experienced subject, the greater the impact of this performance-enhancing effect.

The results obtained for the non-experienced subjects are in contrast to those for experienced subjects. While low ability subjects without experience are not affected by AA, high ability subjects without experience tend to react very positively to AA. For experienced subjects this relation is reversed. This difference in behavior is intuitive because non-experienced subjects with high ability and experienced subjects with low ability are those most affected by the implementation of AA. They are at the margin of competition and thus they are most directly affected by the level playing field imposed through AA. The results for the separate AA treatments in OLS (4) are similar in direction but mainly non-significant. ${ }^{34}$ For non-experienced subjects this conclusion is also verified by analyzing the results of a similar linear regression where the dependent variable is the number of wrongly solved sudokus. Here, low ability students have a significantly lower number of wrongly solved sudokus under AA. This effect decreases for students with higher abilities. ${ }^{35}$

There exists an important literature analyzing how male and female individuals react differently to competition (see Gneezy et al. (2003), Gneezy and Rustichini (2004) and Niederle and Vesterlund (2007)). We here run regressions that control for gender

\footnotetext{
${ }^{33}$ Note that non-experienced subjects were able to solve up to 12 sudokus in the pretest, which implies that the performance-enhancing effect of AA, as expressed by the interaction term "AA*Pretest", is important. For instance, a subject with 11 correct sudokus in the pretest (the highest observed value in the experiment) would statistically solve $14.4(=-1.59+11 * 1.45)$ more sudokus in the tournament with AA than without it.

${ }^{34}$ Again, the reason for the low significance of the AA-treatment dummies in OLS (4) in comparison to the pooled treatment AA in OLS (3) may be due to the small sample size for each treatment.

${ }^{35}$ The linear regression results for ex-ante experienced subjects are less clear and mainly non-significant. Regressions where the number of wrongly solved sudokus is the dependent variable are available upon request.
} 
and its interaction with affirmative action and the ability proxy in order to see if different genders react differently to AA in our tournaments. Table 5 presents regressions OLS (5) and OLS (6) which are extended versions of OLS (1) and OLS (3) for experienced and non-experienced subjects respectively. They are supplemented by the interaction terms “AA*Gender”, "Pretest*Gender” and “AA*Gender*Pretest”.

\begin{tabular}{|c|c|c|}
\hline \multicolumn{3}{|c|}{ Table 5: Correct Sudokus, Affirmative Action and Gender } \\
\hline & Experienced & Non-Experienced \\
\hline & $\begin{array}{c}\text { OLS (5) } \\
\text { Dep. Var: } \\
\text { \# Correct Sudokus }\end{array}$ & $\begin{array}{c}\text { OLS (6) } \\
\text { Dep. Var: } \\
\text { \# Correct Sudokus }\end{array}$ \\
\hline Const & $\begin{array}{c}10.50 \\
(5.34)^{*} \\
\end{array}$ & $\begin{array}{c}11.08 \\
(3.56)^{* * *}\end{array}$ \\
\hline AA & $\begin{array}{c}4.42 \\
(6.51)\end{array}$ & $\begin{array}{c}-5.85 \\
(3.23)^{*}\end{array}$ \\
\hline AA*Pretest & $\begin{array}{l}-0.78 \\
(1.33)\end{array}$ & $\begin{array}{c}2.89 \\
(0.73)^{* * *}\end{array}$ \\
\hline AA*Gender & $\begin{array}{c}8.26 \\
(8.86) \\
\end{array}$ & $\begin{array}{c}8.32 \\
(4.49)^{*}\end{array}$ \\
\hline AA*Gender*Pretest & $\begin{array}{c}1.84 \\
(1.92)\end{array}$ & $\begin{array}{c}-2.78 \\
(1.07)^{* * *}\end{array}$ \\
\hline Pretest*Gender & $\begin{array}{c}1.31 \\
(1.57)\end{array}$ & $\begin{array}{c}3.26 \\
(0.80)^{* * *}\end{array}$ \\
\hline Pretest & $\begin{array}{c}6.425 \\
(1.04)^{* * *}\end{array}$ & $\begin{array}{c}1.76 \\
(0.55)^{* * *}\end{array}$ \\
\hline $\begin{array}{l}\text { Gender } \\
\text { (0=Male,1=Female) }\end{array}$ & $\begin{array}{l}-3.77 \\
(7.07)\end{array}$ & $\begin{array}{c}-9.49 \\
(3.568)^{* * *}\end{array}$ \\
\hline NK & $\begin{array}{c}2.72 \\
(2.50) \\
\end{array}$ & $\begin{array}{l}-0.82 \\
(2.07) \\
\end{array}$ \\
\hline Year & $\begin{array}{c}12.03 \\
(1.64)^{* * *}\end{array}$ & $\begin{array}{c}3.64 \\
(1.19)^{* * *}\end{array}$ \\
\hline Grade & $\begin{array}{c}3.30 \\
(0.72)^{* * *}\end{array}$ & $\begin{array}{c}0.29 \\
(0.67) \\
\end{array}$ \\
\hline \# Observations & 180 & 155 \\
\hline Adj. $\mathrm{R}^{\wedge} 2$ & 0.650 & 0.680 \\
\hline
\end{tabular}

Results for experienced subjects are not statistically significant. However, for non-experienced subjects we find significant gender effects in line with the existent literature, which may partially explain the low significance of results in regressions (3) and (4). Female subjects with low ability perform worse than men with equally low ability since the coefficient for "Gender" in OLS (6) is large, negative, and significant at the $1 \%$ level. However, this effect is reversed for females with higher ability. This can be seen from the fact that the coefficient "Pretest*Gender" is positive and significant at the $1 \%$ level. We also observe that the effect of $\mathrm{AA}$ is different for males and females. The coefficient for "AA" is negative and significant at the $10 \%$ level, implying that low ability non-experienced male subjects decrease their performance in the presence of affirmative action. However, since "AA*Pretest" is positive and significant at the $1 \%$ level, this effect is reversed in males as ability increases. The performance by females is enhanced under AA since the coefficient for “AA*Gender” is positive and significant at 
the $10 \%$ level, independently of the ability level since the significant coefficients at the $1 \%$ level on "AA*Pretest” and “AA*Pretest*Gender” practically cancel out. ${ }^{36}$ Thus, we conclude:

Result 4: Non-experienced females of low ability perform less well than comparable males as long as the asymmetry in experience is not corrected through affirmative action. High ability females perform better than comparable males. Once the disadvantage has been corrected, females improve their performance more than the males.

Finally we look at how subjects' expectations about winning their respective tournament are affected by affirmative action. After the tournament ended but before the participants knew the results, subjects answered a voluntary questionnaire which included questions about their individual perception of the probability of winning their respective tournament. ${ }^{37}$ As there was no information about the identity and characteristics of the respective opponent (with the exception of ex-ante experience in the AA treatments and in treatment K) we use these answers as a measure of confidence in winning. OLS (7) and (8) in Table 6 regress our measure of confidence in winning on "Pretest" and the treatment dummy for affirmative action ("AA"). Understandably, we find that high ability subjects have higher confidence in winning their respective tournament as "Pretest” has a positive and significant coefficient at the $1 \%$ level. More importantly, we find that while for experienced subjects the presence of AA does not significantly affect reported confidence, it significantly increases the confidence of nonexperienced subjects at the $5 \%$ level. These results are consistent with the experienced subjects not feeling frustrated by the introduction of affirmative action while, at the same time, AA correctly increases the expectations of the non-experienced subjects of winning their respective tournament.

\footnotetext{
${ }^{36}$ Similar regressions for separate AA treatments confirmed these results in the sense that all AA treatments had similar effects. The results for those regressions are available upon request.

${ }^{37}$ In the relevant question 6 (see Appendix) students could rank their expectation of winning the tournament against their respective rival on an ordinal scale from 1 ("Definitely") to 5 ("Definitely Not").
} 


\begin{tabular}{|c|c|c|}
\hline \multicolumn{3}{|c|}{$\begin{array}{l}\text { Table 6: Expected Winning Probability, Affirmative } \\
\text { Action and Ability }\end{array}$} \\
\hline & Experienced & Non-Experienced \\
\hline & OLS (7) & OLS (8) \\
\hline & Dep. Var.: & Dep. Var.: \\
\hline & Win Prob. & Win Prob. \\
\hline \multirow[t]{2}{*}{ Constant } & 2.49 & 2.43 \\
\hline & $(0.21)^{* * *}$ & $(0.18)^{* * *}$ \\
\hline \multirow[t]{2}{*}{$\mathrm{AA}$} & -0.12 & 0.34 \\
\hline & $(0.14)$ & $(0.15)^{* *}$ \\
\hline \multirow[t]{2}{*}{ Pretest } & 0.18 & 0.10 \\
\hline & $(0.04)^{* * *}$ & $(0.03)^{* * *}$ \\
\hline \# Observations & 179 & 148 \\
\hline Adj. $\mathrm{R}^{2}$ & 0.086 & 0.069 \\
\hline
\end{tabular}

Notes: * denotes significance at the $10 \%$ level, ${ }^{* *}$ denotes significance at the $5 \%$ and $* * *$ at the $1 \%$ level. One E subject and nine NE subjects did not respond to the questionnaire.

Finally, regressions OLS (9) and OLS (10) show that while confidence is not gender specific for non-experienced subjects, experienced females report a significantly lower measure of confidence in winning than male subjects of the same ability. 


\begin{tabular}{|c|c|c|}
\hline \multicolumn{3}{|c|}{$\begin{array}{l}\text { Table 7: Expected Winning Probability, Affirmative } \\
\text { Action and Gender }\end{array}$} \\
\hline & Experienced & Non-Experienced \\
\hline & OLS (9) & OLS (10) \\
\hline & Dep. Var.: & Dep. Var.: \\
\hline & Win Prob. & Win Prob. \\
\hline \multirow[t]{2}{*}{ Constant } & 2.00 & 2.37 \\
\hline & $(0.31) * * *$ & $(0.23)^{* * *}$ \\
\hline \multirow[t]{2}{*}{$\mathrm{AA}$} & -0.24 & 0.50 \\
\hline & (0.19) & $(0.21)^{* *}$ \\
\hline \multirow[t]{2}{*}{ Gender } & 0.69 & 0.16 \\
\hline & $(0.43)$ & $(0.36)$ \\
\hline \multirow[t]{2}{*}{ AA*Gender } & 0.24 & -0.34 \\
\hline & $(0.29)$ & $(0.31)$ \\
\hline \multirow[t]{2}{*}{ Pretest } & 0.29 & 0.11 \\
\hline & $(0.06)^{* * *}$ & $(0.04)^{* *}$ \\
\hline Pretest* & -0.20 & -0.02 \\
\hline Gender & $(0.08)^{* *}$ & $(0.07)$ \\
\hline \# Observations & 179 & 148 \\
\hline Adj. $R^{\wedge} 2$ & 0.100 & 0.066 \\
\hline
\end{tabular}

Notes: * denotes significance at the $10 \%$ level, ${ }^{* *}$ denotes significance at the $5 \%$ and ${ }^{* * *}$ at the $1 \%$ level. One $\mathrm{E}$ subject and nine NE subjects did not respond to the questionnaire.

\subsection{The Effects of Affirmative Action on the Selection of Tournament Winners}

In the previous subsection we have shown that affirmative action has performance-enhancing effects on both experienced and non-experienced subjects. However, a question remains regarding the efficiency of implementing such policies from an ex-post point of view. As we have seen, AA increases the probability of winning for subjects who have an inherent disadvantage. Thus, those disadvantaged subjects who win their respective tournament may do so not because they perform better than their respective advantaged competitor but because now they receive compensation. As a result, the average performance of those subjects selected as tournament winners may be lower than the one we would have obtained had affirmative action not been implemented. However, given that in our tournament affirmative action had performance-enhancing effects, it is still possible that the comparisons with and without AA may not be clear cut. 
We start by showing that our affirmative action policies "leveled the playing field" at the aggregate level. Table 8 records the percentage of tournaments winners from the NE school as a result of performing all possible pair-wise matches between competitors from both schools in each treatment. ${ }^{38}$ Notice that the percentage of NE tournament winners in the $4^{\text {th }}$ grade $(58.29 \%)$ is higher than in the $6^{\text {th }}$ grade $(45.81 \%)$, suggesting that the sizes of the compensations may have been a bit too high (low) given the performance of $4^{\text {th }}\left(6^{\text {th }}\right)$ graders. Comparing the NK and $K$ treatments with the pooled AA treatments for the whole sample we observe that NE subjects change from representing roughly just $24 \%$ of the tournament winners when there is no affirmative action implemented (NK and $\mathrm{K}$ treatments) to roughly 52\% when it is implemented. This difference is significant at all standard significance levels.

As discussed in the introduction, one possible interpretation of our experiment is that AA may be used in order to select the individuals with highest underlying ability and, thus, we may not want ex-ante experience with the task to matter. Under such an interpretation the results of this subsection allow us to conclude that the AA policies implemented were reasonably successful in correcting the asymmetry and giving an equal chance to individuals of both groups to be selected.

\begin{tabular}{|c|c|c|c|}
\hline \multicolumn{5}{|c|}{ Table 8: Percentage of Non-Experienced Tournament Winners by Treatment and School Year } \\
\hline & $4^{\text {th }}$ Year & $6^{\text {th }}$ Year & Overall \\
\hline NK & $\mathbf{2 5}$ & $\mathbf{2 3 . 8 1}$ & $\mathbf{2 4 . 4 2}$ \\
\hline K & $\mathbf{2 1 . 2 7}$ & $\mathbf{2 7 . 2 7}$ & $\mathbf{2 3 . 9 4}$ \\
\hline AA & $\mathbf{5 8 . 2 9}$ & $\mathbf{4 5 . 8 1}$ & $\mathbf{5 1 . 8 1}$ \\
\hline LH & 83.42 & 57.14 & 31.84 \\
\hline LL & 49.51 & 10.49 & 58.40 \\
\hline PH & 61.43 & 55.03 & 45.96 \\
\hline PL & 40.27 & 53.68 & \\
\hline
\end{tabular}

We now look at the average performance of all possible tournament winners by treatment and school year. Table 9 reports these averages with standard deviations in parenthesis. We find that both when separating by school year and when pooling all data ("Overall”), the average number of sudokus solved correctly by tournament winners is not lower in the AA treatments than in the NK. However, there exists a small negative difference when comparing the AA treatments with respect to the $K$

\footnotetext{
38 Note that the particular match used to reward subjects in our experiment was just one random realization of this process.
} 
treatments, i.e. when looking at the effect of affirmative action on competitors who are aware of the existence of a disadvantage.

\begin{tabular}{|c|c|c|c|}
\hline \multicolumn{4}{|l|}{ School Year } \\
\hline & $4^{\text {th }}$ Year & $6^{\text {th }}$ Year & Overall \\
\hline \multirow[t]{2}{*}{ NK } & 30 & 42.04 & 35.81 \\
\hline & (13.541) & (15.52) & (15.71) \\
\hline \multirow[t]{2}{*}{ K } & 31.83 & 46.91 & 37.75 \\
\hline & (11.62) & (13.03) & (14.23) \\
\hline \multirow[t]{2}{*}{$\mathrm{AA}$} & 29.70 & 43.36 & 36.53 \\
\hline & (13.35) & (12.53) & (14.63) \\
\hline \multirow[t]{2}{*}{ LH } & 28.20 & 42.91 & 36.22 \\
\hline & (11.98) & (12.58) & (14.31) \\
\hline \multirow[t]{2}{*}{ LL } & 29.75 & 51.09 & 38.54 \\
\hline & (12.79) & (11.12) & (16.04) \\
\hline \multirow[t]{2}{*}{$\mathrm{PH}$} & 27.94 & 41.30 & 33.90 \\
\hline & (11.00) & $(12.80)$ & (13.56) \\
\hline \multirow[t]{2}{*}{ PL } & 32.56 & 41.08 & 37.36 \\
\hline & (16.27) & (11.51) & (14.41) \\
\hline
\end{tabular}

Note that since we are implementing all possible matches within each treatment, the sample size increases exponentially and thus statistical tests are now more powerful. Table 10 records the percentage change in these averages between treatments as well as Mann-Whitney tests comparing these differences. A negative sign indicates that the first treatment compared has a lower average than the second treatment compared.

\begin{tabular}{|l|c|c|c|}
\hline \multicolumn{4}{|c|}{ Table 10: Percentage Change of the Average Correct Sudokus by Tournament Winners } \\
\hline & $4^{\text {th }}$ Year & $6^{\text {th }}$ Year & Overall \\
\hline NK Vs. K & $-5.76^{* *}$ & $-10.38^{* * *}$ & $-5.14^{* *}$ \\
\hline NK Vs. AA & 1.02 & $-3.05^{* *}$ & $-1.95^{*}$ \\
\hline K Vs. AA & $7.19^{* *}$ & $8.17^{* * *}$ & 3.36 \\
\hline
\end{tabular} Notes: ${ }^{*}$ denotes significance differences at the $10 \%$ level, ${ }^{* *}$ denotes significance at the $5 \%$ and ${ }^{* *}$ at the $1 \%$ level.

Notice that when comparing the NK with the AA treatment, performance is in fact a significant $1.95 \%$ higher (at the $10 \%$ level) when affirmative action is in place and data from both school years are pooled. Performance decreases by a non-significant 3.36\% when comparing AA with $\mathrm{K}$ for the overall data. When comparing the data separating for different school years we maintain the conclusion that the average performance by tournament winners was higher in AA than in NK for $6^{\text {th }}$ year subject but not significantly so for $4^{\text {th }}$ year subjects. However, when we compare $K$ with AA controlling for school year we find that there was a significant loss in each school year when AA was implemented (a loss of $7.19 \%$ for $4^{\text {th }}$ year and a of $8.17 \%$ for $6^{\text {th }}$ year). 
This indicates that there was a loss in average performance although it was not large. ${ }^{39}$ Thus we conclude:

Result 5: While affirmative action policies induced a level playing field, they did not do so at the expense of a large loss in average performance by subjects selected as tournament winners.

\section{Conclusion}

This paper contributes to the debate on the adequacy of affirmative action policies by presenting evidence on the effects in individual performance of implementing these policies in a tournament where capacities to compete are asymmetric. In particular, it shows that levelling the playing field by implementing AA leads to performance improvements by almost all participants and to a small decline in the average performance of selected winners.

Our results thus imply that there are circumstances under which affirmative action policies are beneficial with respect to the incentives provided to all participants. Additionally, the negative effects of selecting worse performing but disadvantaged subjects are minimal.

There are several issues that our design does not allow us to discuss. For example it is important to study how other relevant disadvantages not directly affecting capacities to compete may be affected by affirmative action. Similarly, the long term effects of using affirmative action have not been analyzed here. These issues are important and are left for future research.

\footnotetext{
${ }^{39}$ Notice that performance is a significantly lower $7 \%$ when comparing the performance by tournament winners under AA with respect to the hypothetical situation in which affirmative action was announced (such that the performance inducing effects are present) but then not used to select tournament winners. Notice that such policy, although more efficient from a performance point of view, may be difficult to justify and not credible in the long term.
} 


\section{References}

Apesteguia, J., and Palacios-Huerta, I., (2008). "Psychological Pressure in Competitive Environments: Evidence from a Randomized Natural Experiment”. Universitat Pompeu Fabra. Mimeo.

Balart, P., (2009). "Equality of Opportunities and Welfare in a Model of Job Allocation”. Universitat Autònoma de Barcelona. Mimeo.

Calsamiglia, C., (2009). "Decentralizing Equality of Opportunity”. International Economic Review 50(1): 273-290.

Coate, S., and Loury, S., (1993), "Will Affirmative-Action Policies Eliminate Negative Stereotypes?”. American Economic Review 83(5): 1355-1360.

Che, Y., and Gale, I., (1998). “Caps on Political Lobbying”. American Economic Review (88): 643-651

Franke, J., (2008). "Does Affirmative Action Reduce Effort Incentives? A Contest Game Analysis”. UAB and IAE Working Paper Series 711.07.

Fryer, R. G. J., and G. C. Loury, (2005a). "Affirmative Action in Winner-Take-All Markets.” Journal of Economic Inequality 3(3): 263-280.

Fryer, R. G. J., and G. C. Loury, (2005b). “Affirmative Action and Its Mythology”. Journal of Economic Perspectives 19(3): 147-162.

Fu, Q., (2006). “A Theory of Affirmative Action in College Admissions”. Economic Inquiry 44: 420-428.

Gneezy, U., Niederle M., and A. Rustichini, (2003). "Performance in Competitive Environments: Gender Differences”. Quarterly Journal of Economics 118(3): 10491074.

Gneezy, U., and A. Rustichini, (2004). "Gender and Competition at a Young Age," American Economic Review Papers and Proceedings: 377-381.

Harbaugh, W., and Krause, K., (2000). "Children's Altruism in Public Good and Dictator Experiments,” Economic Inquiry 38(1): 95-109.

Harbaugh, W., Krause, K. and T. R. Berry, (2001). “GARP for Kids. On the Development of Rational Choice Behavior”. American Economic Review 91(5): 15391545.

Hickman, B. R., (2009). "Effort, Achievement Gaps and Affirmative Action: A New Look at College Admissions”. University of Iowa. Mimeo.

Hoff, K., and P. Pandey, (2006). "Discrimination, Social Identity, and Durable Inequalities”. American Economic Review 96(2): 206-211. 
Holzer, H., and D. Neumark, (2000) “Assessing Affirmative Action”. Journal of Economic Literature 38(3): 483-568.

Krasnokutskaya, E., and K. Seim, (2007). "Determinants of the Participation Decision in Highway Procurement Auctions”. University of Pennsyilvania. Mimeo.

Lazear, E..P., and S. Rosen, (1981). "Rank-Order Tournaments as Optimum Labor Contracts”. Journal of Political Economy 1989(5): 841-864.

Marion, J., (2007). "Are Bid Preferences Benign? The Effect of Small Business Subsidies in Highway Procurement Auctions”. Journal of Public Economics 91: 15911624.

Miller, A., and Segal, C., (2008). "Do Temporary Affirmative Action Programs Produce Permanent Effects? A Study of Minority and Female Employment in Law Enforcement Agencies”. Universitat Pompeu Fabra. Mimeo.

Myerson, R., (1981): “Optimal auction design”, Mathematics of Operations Research 6: 58-73.

Niederle, M., C. Segal and L. Vesterlund, (2008). "How Costly is Diversity? Affirmative Action in Competitive Environments”. Universitat Pompeu Fabra. Mimeo.

Niederle, M., and L. Vesterlund, (2007). "Do Women Shy Away From Competition? Do Men Compete Too Much?”. Quarterly Journal of Economics 122(3): 1067-1101.

Prendergast, C., (1999). "The Provision of Incentives in Firms”. Journal of Economic Literature 37(1): 7-63.

Schotter, A., and K. Weigelt, (1992). "Asymmetric Tournaments, Equal Opportunity Laws, and Affirmative Action: Some Experimental Results”. Quarterly Journal of Economics 107(2): 511-39.

Sowell, T., (2004). Affirmative Action around the World: An Empirical Study. New Haven, Conn: Yale University Press. 


\section{Appendix}

\section{Experimental Instructions}

Below you can find a translation of the experimental instructions for one of the treatments (Experienced students in treatment $\mathrm{PH}$ ). Other treatments' instructions were identical, although changing the size and type of compensation. Complete instructions are available upon request. Instructions were originally written in Spanish.

\section{Pre-instructions}

Your Code:

Thank you for participating. First, we are going to explain what you will be doing. You have to fill in grids with the numbers 1, 2, 3 and 4.

To do this you have to use the following rules:

1. All boxes in a grid must be filled in with a number.

2. The same number can appear only once in each column (vertical).

3. The same number can appear only once in each row (horizontal).

4. The same number can appear only once in each square. Each grid is divided in 4 squares, marked in bold lines.

5. In each grid all numbers $\mathbf{1}, \mathbf{2 ,} \mathbf{3}$ and $\mathbf{4}$ must be in each column, each row, and each square.

Here are some examples:

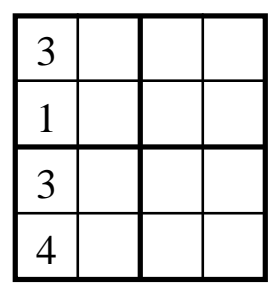

This column is completed wrongly because the 3 appears twice (rule 2)

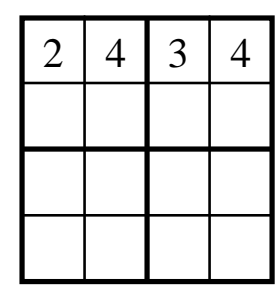

This row is completed wrongly because the 4 appears twice (rule 3)

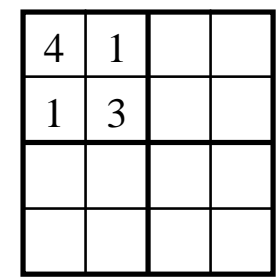

This square is completed wrongly because the 1 appears twice (rule 4)

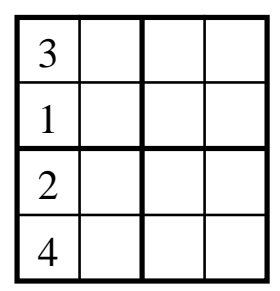

This column is completed correctly.

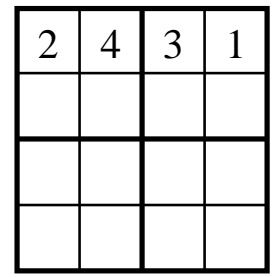

This row is completed correctly.

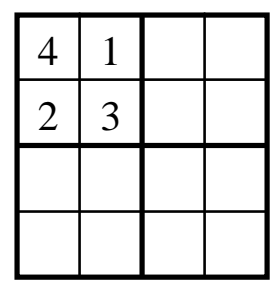

This square is completed correctly. 
This is an example of a correctly completed grid.

\begin{tabular}{|l|l|l|l|}
\hline 4 & 1 & 2 & 3 \\
\hline 2 & 3 & 4 & 1 \\
\hline 3 & 4 & 1 & 2 \\
\hline 1 & 2 & 3 & 4 \\
\hline
\end{tabular}

Before starting you have 5 minutes to complete the following grids to check whether you have understood the rules. We will give you the correctly completed grids after the 5 minutes period.
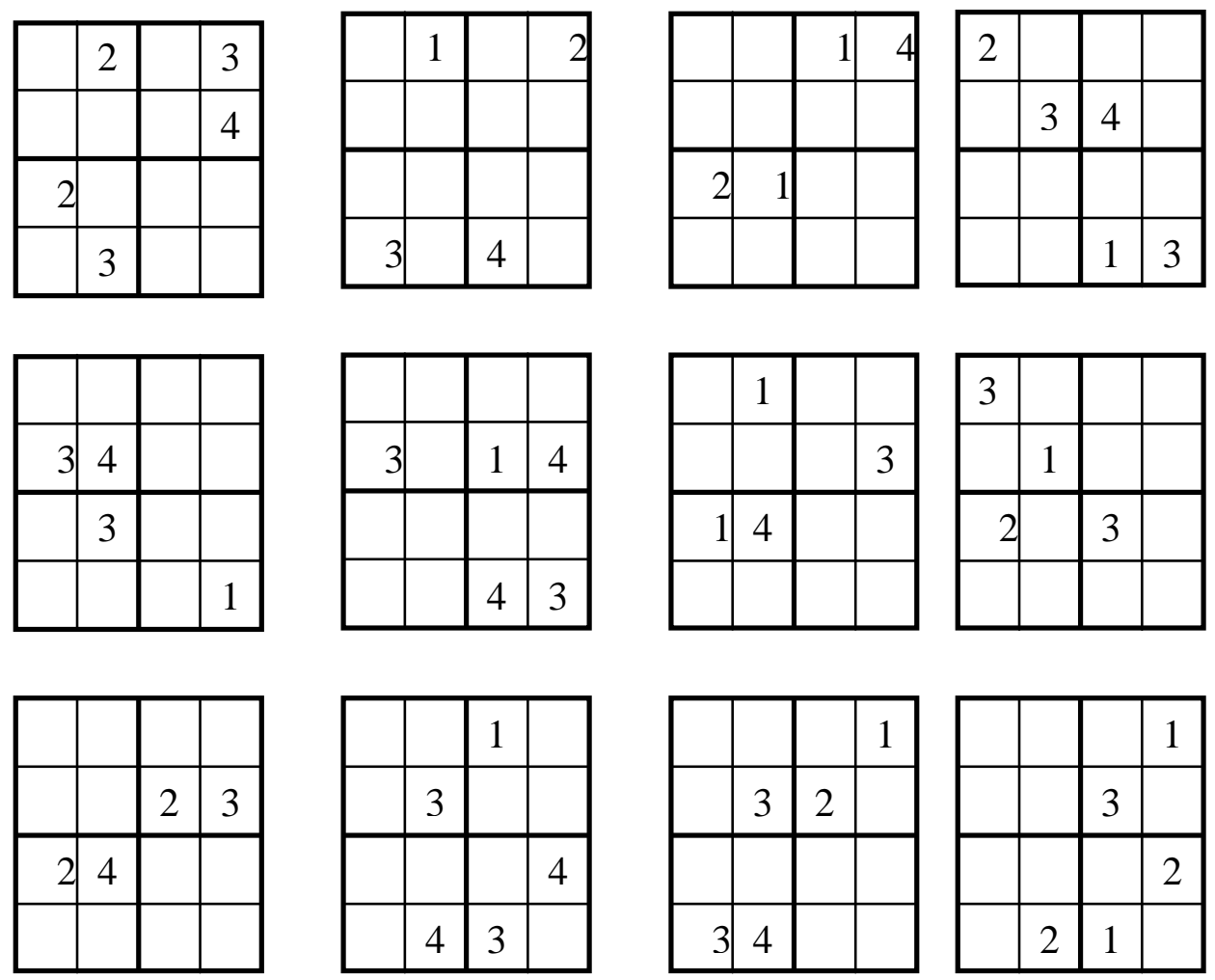

Please remain silent and on your seat without disturbing anyone during the whole practice.

Raise your hand after you have finished all grids and we will pick them up.

Good luck!

\section{Instructions (treatment PH)}

Your Code:

You are randomly matched with another student (your matched participant) from another school similar to yours, who is completing the same grids as you are.

The students at the other school have NOT learned before how to solve those types of grids because it was NOT taught to them in their math classes.

You have now 30 minutes time to complete as many grids as possible with the numbers $\mathbf{1}, \mathbf{2}, \mathbf{3}$ and $\mathbf{4}$ on the formulaires that we are now going to distribute.

We will compare how many grids you have solved correctly with the number of correctly solved grids by your matched participant from the other school:

- $\quad$ If you have correctly solved more grids then you will earn a $7 \mathrm{EU}$ voucher that you can redeem in "La Casa del Libro", where you can buy books, collector's cards, toys, music or comics. 
- $\quad$ If you have correctly solved less grids then you will not earn the voucher.

- If you have correctly solved the same number of grids then a toss of a coin will be used to determine who earns the voucher.

To compensate the other students for the fact that they have less practice than you we are going to give them 1 grid more for each grid that they have solved correctly.

For example:

- If your matched participant correctly solves 12 grids, they count as $12+12=24$ grids. Therefore will earn the voucher if you solve correctly 25 grids or more.

- $\quad$ If your matched participant correctly solves 30 grids, they count as $30+30=60$ grids. Therefore you will not earn the voucher if you solve correctly 59 grids or less.

- If your matched participant scorrectly solves 20 grids, they count as $20+20=40$ grids. Therefore, if you solve correctly 40 grids, a toss of a coin determines whether you earn the voucher.

The numbers of this example are chosen by chance and do not indicate how many grids a student can solve correctly. We would like to inform you that we have studied the results of other students of your age from other schools who completed the same grids: The maximum number of grids that somebody managed to solve correctly in 30 minutes were 81 grids and the minimum was 0 grids. On average the students completed around 25 grids correctly.

Remember that only correctly solved grids count.

Wait to turn the answer sheet until we tell you to do so. You have 30 minutes . Good luck!

\section{Your Code:}

Thank you for your participation.

\section{Final Questionnaire}

Please answer the following questions:

1. How did you find today's task?

Interesting Entertaining A bit long Boring

2. How many grids like these have you tried before?

None Between 1 and 5 Between 6 and $20 \quad$ Between 20 and $40 \quad$ More than 40

3. If you have tried solving grids like these before, where did you do it?

4. How many grids do you think you have solved correctly today?

5. How many grids do you think your partner of the other school has solved correctly?

6. Do you think you are going to get the voucher?

Definitely Probably yes I don’t know Probably not Definitely not

7. Do you think it was a good idea to compensate the students of the other school that did not do grids like this before in school?

YES NO

8. The competition with the students of the other school from my perspective seemed to be:

Fair Rather Fair A bit Unfair Unfair Rather Unfair Very Unfair

9. Any other comment? 